\title{
ATP1A3 Gene Mutation in Rapid Onset Dystonia Parkinsonism (RDP) And Alternating Hemiplegia of Childhood (AHC) Syndromes
}

\author{
Behzad Saberi*, Behrouz Saberi Tehrani \\ Department of Preventive and Community Medicine, Iran \\ *Corresponding author: Behzad Saberi, Department of Preventive and Community Medicine, Iran \\ To Cite This Article: Behzad Saberi. ATP1A3 Gene Mutation in Rapid Onset Dystonia Parkinsonism (RDP) And Alternating Hemiplegia of \\ Childhood (AHC) Syndromes. Am J Biomed Sci \& Res. 2019 - 2(3). AJBSR.MS.ID.000587. DOI: 10.34297/AJBSR.2019.02.000587
}

Received: March 25, 2019 | Published: April 10, 2019

\section{Mini Review}

Rapid onset Dystonia Parkinsonism (RDP) syndrome belongs to the dystonia-parkinsonism syndromes group. The clinical symptoms usually develop during some minutes to some weeks and then will go on a stable manner. The symptoms are related to parkinsonisms and dystonia. Sometimes symptoms of dystonia would continue for years until parkinsonisms related symptoms appear. Sometimes seizures and some psychiatric symptoms would appear among other symptoms, but such findings are rare. Risus sardonicus, slurred speech, dysphasia and fixed smile can be seen in this syndrome. The symptoms related to parkinsonism would not give any response to levodopa treatment. Physical and emotional stresses can trigger the appearance of symptoms which the usual onset of symptoms appearance would be among adolescents and young adults [1-3].

Mutation in ATP1A3 gene which belongs to ATPase genes group, can be seen in this syndrome. Since the syndrome can be inherited or sporadic, such gene mutation would be responsible for some inherited and apparently sporadic patterns. ATP1A3 gene would regulate transportations of potassium and sodium ions through specific cell membranes. It has autosomal dominant inheritance with reduced penetration pattern. Alternating Hemiplegia of Childhood (AHC) is another pathology which is caused by mutations in ATP1A3 gene. Although Alternating Hemiplegia of Childhood (AHC) syndrome has different targeting age specifically at onset, and different course of progression, but it may be possible that Rapid onset Dystonia Parkinsonism and Alternating Hemiplegia of Childhood would belong to a same spectrum. Although AHC onset may be after 18 months of age in comparison with RDP which may start before 18 months of age, but seeing the same gene mutation patterns can be helpful to recognize some specific symptoms related to each pathologies and find some specific features related to each syndrome in clinical practice like bulbar involvement, oculogyria, dysphagia, sudden appearance of dystonia and parkinsonism features and relevant triggers [4-7].

Acknowledgement

None.

\section{Conflicts of Interest}

No conflicts of interest.

\section{References}

1. Rosewich H, Ohlenbusch A, Huppke P, Schlotawa L, Baethmann M, et al. (2014) The expanding clinical and genetic spectrum of ATP1A3-related disorders. Neurology 82(11): 945-955.

2. Fahn S (2011) Classification of movement disorders. Mov Disord 26(6): 947-957.

3. Asmus F, Gasser T (2010) Dystonia-plus syndromes. Eur J Neurol 17(S1): 37-45.

4. Geyer HL, Bressman SB (2011) Rapid-onset dystonia-parkinsonism. Handb Clin Neurol 100: 559-562.

5. Carvalho Aguiar PM De, Ozelius LJ (2002) Classification and genetics of dystonia. Lancet Neurology 1(5): 316-325.

6. Frucht SJ, Houghton WC, Bordelon Y, Greene PE, Louis ED (2005) A single-blind, open-label trial of sodium oxybate for myoclonus and essential tremor. Neurology 65(12): 1967-1969.

7. Panagiotakaki E, Gobbi G, Neville B, Ebinger F, Campistol J, et al. (2010) Evidence of a non-progressive course of alternating hemiplegia of childhood: study of a large cohort of children and adults. Brain 133(12): 3598-3610. 